\title{
Research on the Interaction Mechanism between Landslide and Tunnel Engineering
}

\author{
Yufang Zhang $\left(\mathbb{D},{ }^{1}\right.$ Jian Li $\mathbb{D}^{1},{ }^{1}$ Hongyu Liu $\mathbb{D}^{2},{ }^{2}$ Wei Li $\left(\mathbb{D},{ }^{1}\right.$ Jiaming Li $\mathbb{D}^{1},{ }^{1}$ and Lijie Hou $\mathbb{D}^{1}$ \\ ${ }^{1}$ Railway Engineering Research Institute, China Academy of Railway Sciences Group Co. Ltd., Beijing 100081, China \\ ${ }^{2}$ School of Energy and Mining Engineering, China University of Mining and Technology (Beijing), Beijing 100083, China \\ Correspondence should be addressed to Jian Li; 118838978987@126.com
}

Received 2 September 2021; Accepted 12 November 2021; Published 27 November 2021

Academic Editor: Alicia E. Ares

Copyright (C) 2021 Yufang Zhang et al. This is an open access article distributed under the Creative Commons Attribution License, which permits unrestricted use, distribution, and reproduction in any medium, provided the original work is properly cited.

The landslide at the entrance of a railway tunnel is large scale, and serious diseases are prone to appear under natural disasters, which threaten the safety of the tunnel. According to its characteristics, on-site long-term monitoring experiments and numerical analysis were carried out, and the mechanism of interaction between landslide and tunnel engineering was analyzed. The results show that under the impact of rainfall and earthquake, the original internal stress balance in the landslide body is disturbed, leading to the increase in landslide thrust and damage of the tunnel lining. Simultaneously, the excavation of the tunnel can slack the surrounding rock to increase the landslide thrust and make the landslide be finally formed; this landslide conversely acts on the tunnel, resulting in deformation and destruction of the tunnel. During the monitoring, under the influence of rainfall and earthquake, the stress of the secondary lining was continuously increased by $25 \%$. Tunnel construction caused a maximum deformation of $30 \mathrm{~mm}$ in the antislide pile at a distance of $2.12 \mathrm{~m}$, and the slope and the tunnel were also affected. Under extreme conditions such as rainfall and earthquake, shear failure occurred at the vault, bottom, and waist of the right-line tunnel located at the junction of soil and rock; at this time, the tensile strength of the tunnel reached $93.8 \%$ of the limit value of concrete, which seriously affected the safety of the tunnel. As for the weakened tunnel structure, measures such as dense planting and strengthening of concrete strength should be adopted to enhance the safety of the tunnel structure.

\section{Introduction}

As the Chinese railway is gradually constructed in the mountainous area, linear projects such as tunnels will inevitably pass through poorly cut geological bodies. The weak engineering geological body often exists at the entrance and exit of the tunnel, where tunnel excavation can easily induce geological disasters such as landslides and collapses. At the same time, these disasters seriously affect the safety of tunnels and railways [1-3].

Aiming at the interaction between landslides and tunnels, many experts have conducted deep studies. The tunnellandslide system is divided into three types such as parallel, orthogonal, and oblique according to the relative position. The force on the tunnel is related to its relative position in the landslide, which means that this relative position relationship is the main factor determining the interaction mode and force mode; furthermore, the tunnel force is the root cause of the tunnel deformation; that is, the relative position relationship between the tunnel and the sliding surface determines the interaction mode and deformation characteristics of the landslide and the tunnel [4-7].

At present, the main methods for studying this interaction include theoretical analysis, model test, and numerical analysis. Theoretical analysis is mainly to analyze the law of deformation and force and their influencing factors in the landslide deformation zone by constructing mechanical models of rock-tunnel structure based on this relative position relationship [8-10]; the model test is mainly to verify the interaction mechanism through laboratory tests and large-scale model tests [11-16]; numerical analysis is mainly to calculate and analyze the interaction mechanism under the influence of different factors and working conditions such as rainfall earthquake tunnel construction based on 
numerical calculation software such as finite element discrete element finite difference [17-21].

However, at present, researchers mostly carry out research qualitatively from the aspects of relative position relationship and influence mechanism but seldomly quantitatively. In this paper, based on a railway, the mechanism of landslide-tunnel interaction is studied using long-term onsite monitoring and numerical calculation.

\section{Overview of Long-Term Monitoring Trials}

\subsection{The Introduction of Project Site}

2.1.1. Relative Spatial Position of Landslide and Tunnel. A railway tunnel is located in the famous Longmenshan structural belt in China, it is a giant nappe structural belt with complex structure, and the overall direction is NE45. This tunnel crosses the mountain at an angle of about $60^{\circ}$. The terrain of crossed area can be divided into the middle mountain landform and the high mountain landform, as shown in Figures 1 and 2.

2.1.2. Analysis of Characteristics of Landslide Disaster. The entrance of the tunnel has a front edge of about $300 \mathrm{~m}$ wide and a slope length of $150-200 \mathrm{~m}$. The deepest the sliding surface can reach about $23 \mathrm{~m}$. The volume is about $120 \times 104 \mathrm{~m}^{3}$, and the longitudinal slope is steep with a slope of $40 \sim 55$.

According to the on-site investigation, the two main potential diseases include material on the slope surface is relatively loose, and it is easy to form debris flow in the rainy season; tunnel excavation may cause shallow layer slippage, collapse, and other disasters, as shown in Figure 3.

There are two arc-shaped tensile cracks at the rear edge of the landslide with the maximum width of $1.2 \mathrm{~m}$, which is judged to be caused by the previous earthquake; this indicates that there occurred shallow deformation in the slope and in a stable state during the survey, but the adverse deformation may also happen under the influence of rainfall, earthquake, and tunnel construction, as shown in Figure 4.

2.1.3. Overview of Tunnel Engineering Design. The tunnel traverses the Longmen Mountain range in the northeast direction about $\mathrm{NE} 40^{\circ}$. The tunnel crosses the mountain range at an angle of about $60^{\circ}$. The entrance of the tunnel is designed as an open tunnel. The landslide body is protected by anchor cable antislide pile and anchor (cable) frame beam.

\subsubsection{Preliminary Analysis and Comprehensive Evaluation of} the Interaction between Landslide and Tunnel Engineering. According to the on-site survey, the landslide and the tunnel have obvious mutual influence. Under the condition of rainfall or earthquake, the slope becomes more easily unstable, which will induce landslide and have a serious impact on the tunnel stability. During the tunnel construction, the landslide may be activated and affect the landslide stability. Therefore, it is urgent to carry out quantitative research on
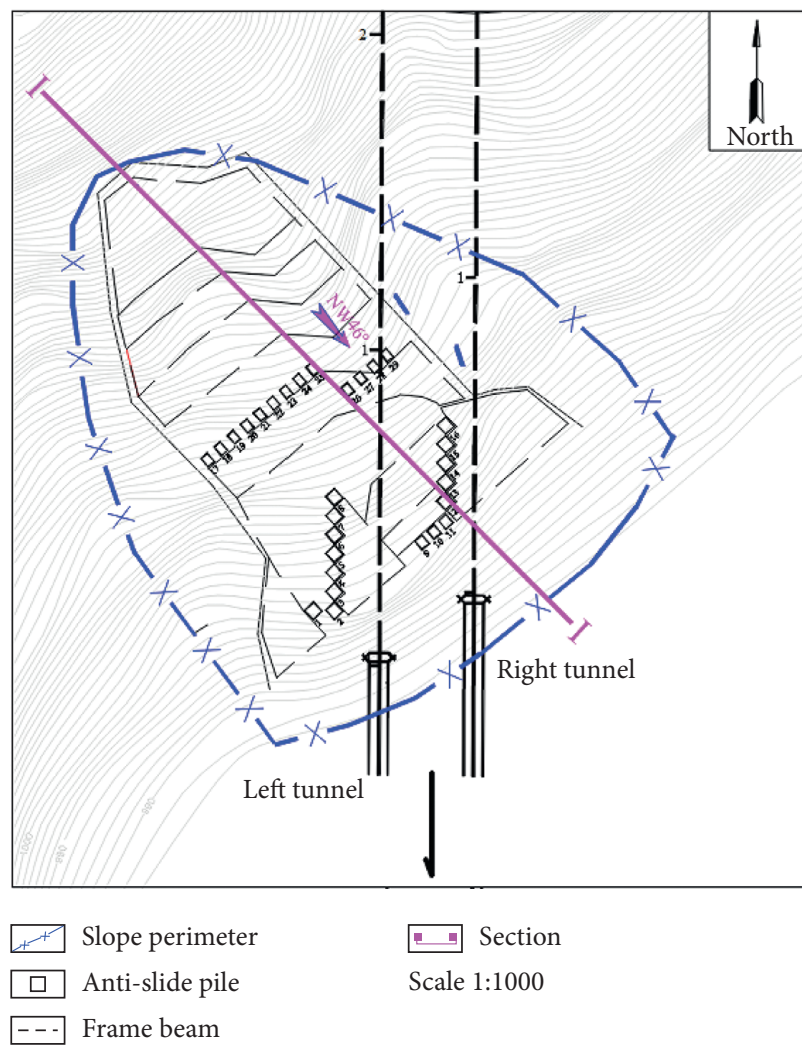

FIGURE 1: Engineering geological layout of the landslide.

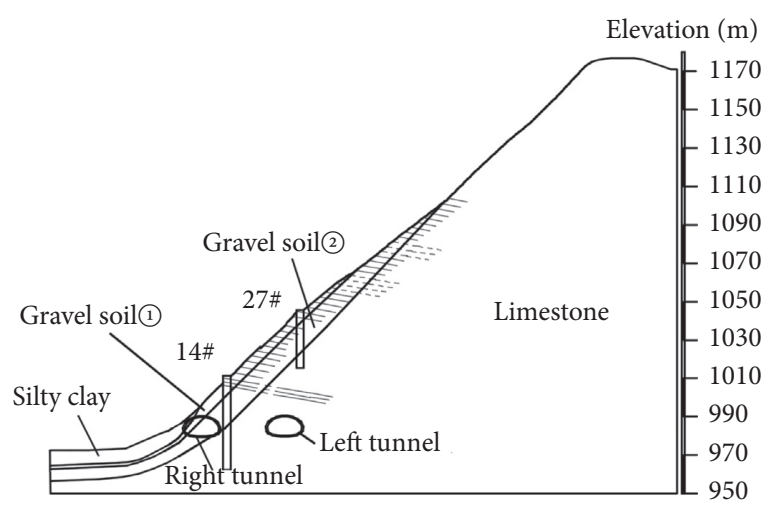

- - Anchor cable frame beam

- Anchor frame beam

-. Anchor rope

[] Anti-slide pile

FIgURE 2: Engineering geological section of the landslide.

the interaction between landslide and tunnel engineering on-site.

\subsection{Design of Long-Term Monitoring Test Scheme}

\subsubsection{The Design of the Test Program}

(1) The Monitorization Scheme. Field monitoring tests include deep displacement measurement of slope, stress measurement of antislide pile retaining structure, and 


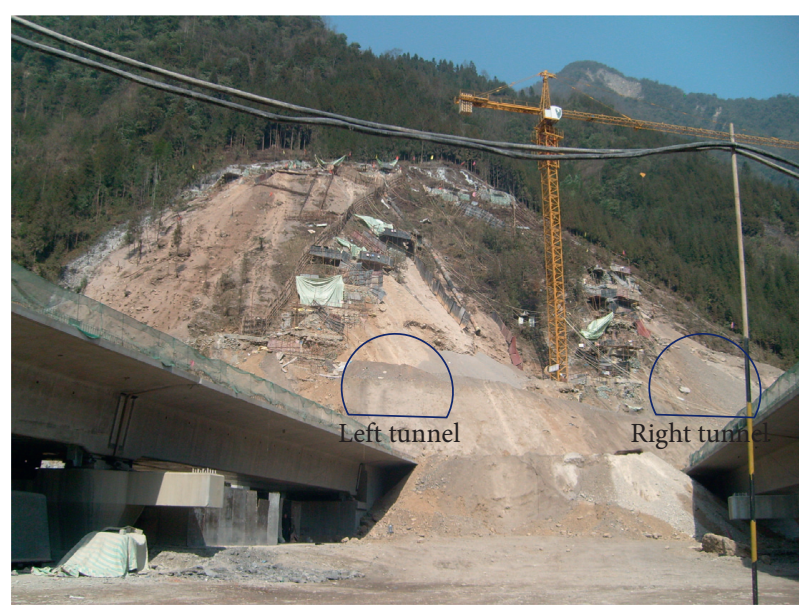

Figure 3: Landslide site.

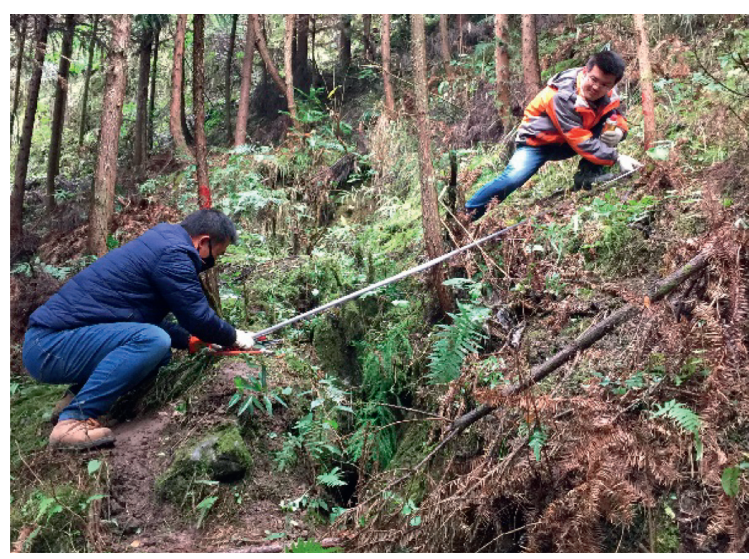

Figure 4: In situ arc fracture.

internal force measurement of tunnel primary support and secondary lining.

(2) The Numerical Simulation. During the numerical calculation using FLAC3D software, the Moore-Coulomb constitutive is adapted to the soil, and the antislide pile is simulated by the solid element; the anchor rod adopts the pile element simulation; the anchor cable adopts the cable element simulation; the model's bottom is fixed, and the slope surface is a free; the normal displacement of the model is restrained, as shown in Figure 5.

According to the geological conditions of the site, the formation parameters are selected. According to the $3.7 \mathrm{~mm}$ deformation of the 14\# antislide pile after the earthquake, the parameter inversion is carried out through numerical calculation. The difference between the numerical calculation inversion result and the field measured data is $1 \mathrm{~mm}$. Therefore, the value of the formation parameter is considered reasonable. The calculation result as shown in Figure 6 and the values of stratum parameters are shown in Table 1.

\subsubsection{Scheme of Long-Term Monitorization}

(1) Rainfall Condition. The tunnel is located in an alpine climate zone in northwest Sichuan; it is dominated by the cold temperate climate with an average annual temperature of $4-12^{\circ} \mathrm{C}$. The annual precipitation is $500 \sim 900 \mathrm{~mm}$, and the average annual precipitation in 30 years is $731.226 \mathrm{~mm}$. The rainy season is from early June to mid-September, accounting for about $50 \% \sim 60 \%$ of the annual amount.

Rainfall will make the water content of the slope soil increase, leading to a reduction of cohesion force and internal friction angle, resulting in slope instability. In order to simulate the most unfavourable working conditions, the parameters of saturated soil are selected to reflect extreme rainfall condition.

(2) Earthquake Condition. On May 12, 2008, a 8.8-magnitude earthquake occurred in Wenchuan County, Aba Prefecture, Sichuan Province. On August 8, 2017, a 7.0magnitude earthquake occurred in Jiuzhaigou County, Aba Prefecture, Sichuan Province. The earthquake intensity in the area where the tunnel is located is 6.0.

The quasistatic method is used to conduct seismic analysis of the slope, and the peak acceleration of the site vibration in the area where the worksite is located (Gaochuan Township) is $0.2 \mathrm{~g}$. The basic acceleration $\alpha$ of the horizontal earthquake is taken as a rare earthquake with a fortification intensity of 8 degrees $0.2 \mathrm{~g}$, and the comprehensive horizontal earthquake coefficient $\alpha \mathrm{w}$ is taken as 0.05 .

(3) Construction Condition. The construction of the tunnel is divided into three steps. The upper step started on September 5, 2016, the lower-right step started on September 7, 2016, and the lower-left step started on September 8, 2016; the construction of the invert and initial support is from September 25, 2016, to September 26, 2016; the second lining was constructed on November 5, 2016.

In the process of tunnel excavation and construction, the stress balance of the landslide body was broken due to the blasting and mechanical vibration, leading to the instability of the slope body and deformation of the antisliding retaining structure. The design of construction condition is realized by simulating the excavation of tunnel.

\section{Long-Term Monitoring Analysis of Influence of Landslide on Tunnel Engineering}

\subsection{Long-Term Monitoring and Analysis of the Influence of Landslide on the Tunnel under Rainfall Condition}

3.1.1. Analysis of Actual Rainfall Condition. As shown in Figure 7, during the rainy season, the relative displacement of the antislide pile decreases with the depth, and the maximum surface deformation is less than $3 \mathrm{~mm}$, indicating that the antislide pile has a good retaining effect, and the 


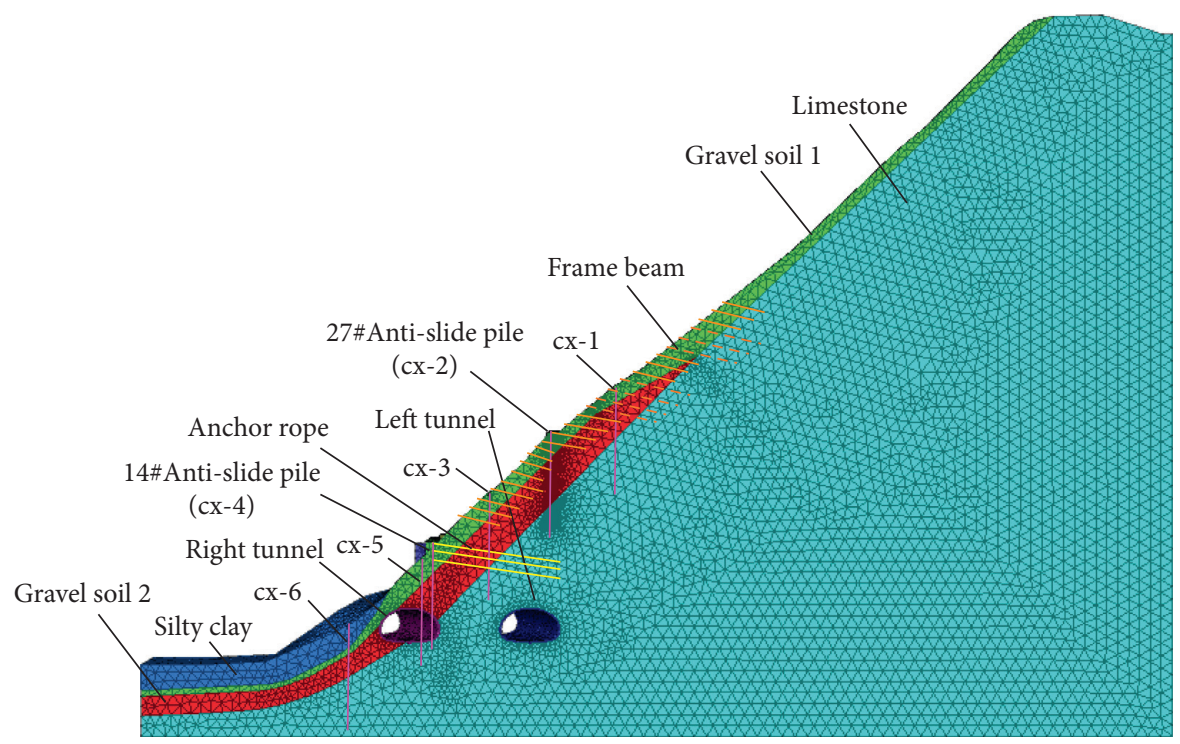

Figure 5: Numerical calculation model.

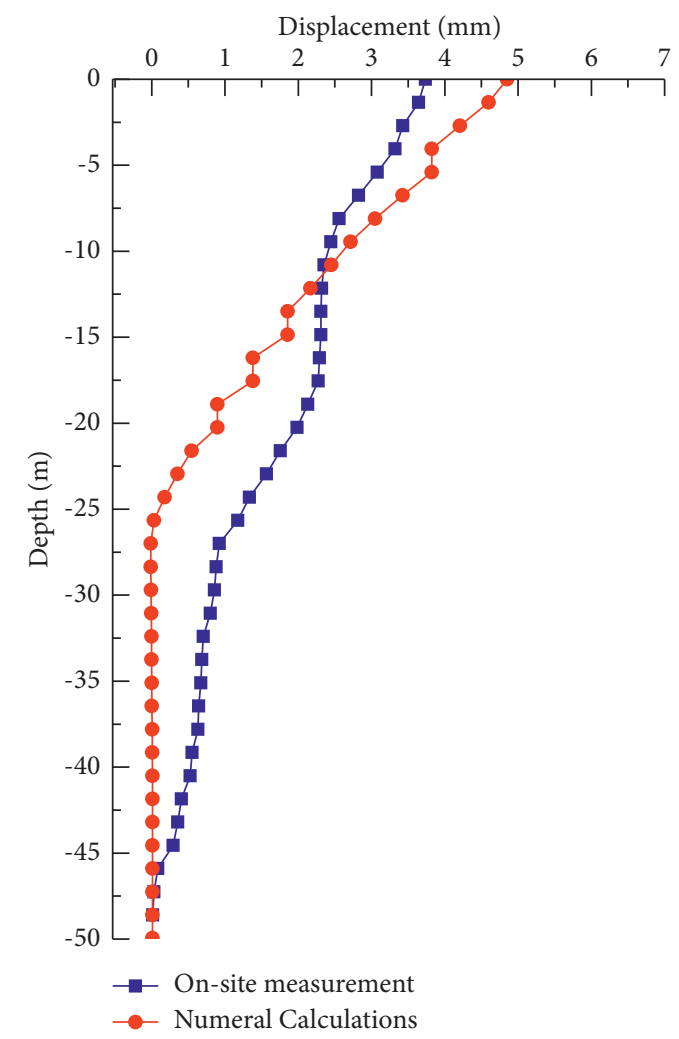

Figure 6: Numerical calculation inversion results.

landslide body is in a stable state under normal rainfall condition.

As shown in Figure 8, under this condition, the stress of the antislide pile shows a increasing trend with small growth rate, and the maximum daily increase is $52.4 \mathrm{KPa}$, indicating that the landslide thrust increases under the impact of rainfall, and the antislide pile plays a good role of retaining and keeping stable state when the landslide thrust is transferred to the antislide pile.

As shown in Figure 9, during the rainy season in 2017, the initial tunnel stress decreased by $2.18 \mathrm{MPa}$, accounting for $14.1 \%$, and the average daily decrease was $30.28 \mathrm{KPa}$; during the rainy season in 2018, the initial tunnel stress decreased by $3.14 \mathrm{Mpa}$, accounting for $14.7 \%$, and the 
TABle 1: Physical and mechanical parameters of stratum around tunnel.

\begin{tabular}{lccccc}
\hline Soil type & $\begin{array}{c}\text { Weight } \\
\left(\mathrm{kN} / \mathrm{m}^{3}\right)\end{array}$ & $\begin{array}{c}\text { Elastic modulus } \\
(\mathrm{MPa})\end{array}$ & $\begin{array}{c}\text { Poisson's ratio } \\
\text { Friction angle } \\
\left({ }^{\circ}\right)\end{array}$ & $\begin{array}{c}\text { Cohension force } \\
(\mathrm{KPa})\end{array}$ & 30 \\
\hline Silty clay & 19 & 40 & 0.2 & 25 & 20 \\
Gravelly soil 1 & 20 & 200 & 0.2 & 30 & 30 \\
Gravelly soil 2 & 20 & 250 & 0.2 & 1000 & 55 \\
Limestone & 27 & 25000 & 0.25 & & 30 \\
\hline
\end{tabular}

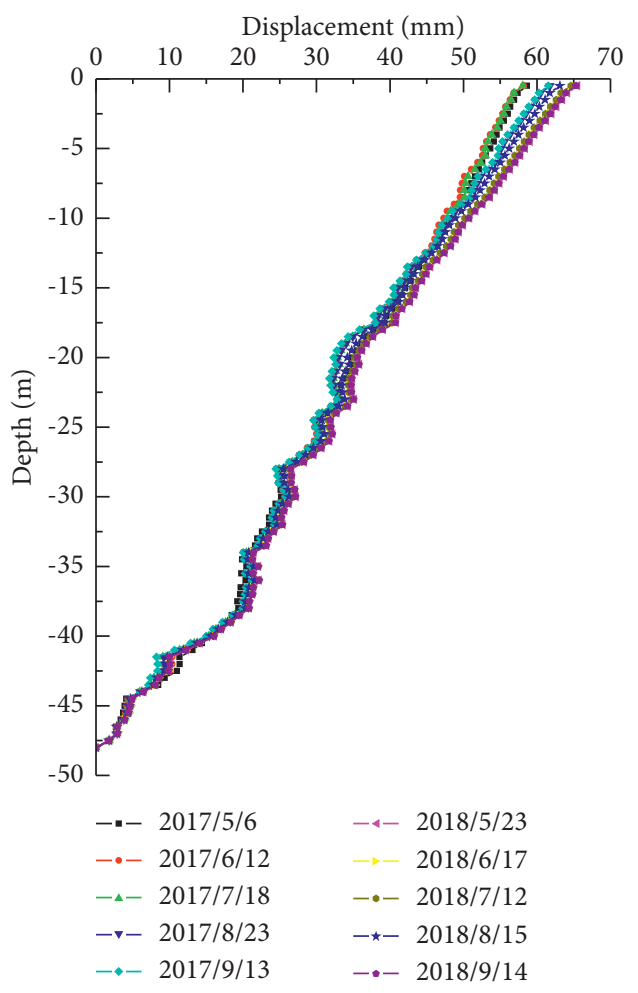

FIGURE 7: Monitoring curve of deep displacement of 14\# antislide pile during the rainy season.

average daily decrease was $41.19 \mathrm{KPa}$. Basically, the stress change is stable, and the change is small; this shows that under the effect of rainfall, except for the increase in landslide thrust consumed by the antislide pile, the remaining landslide thrust does not have a significant impact on the tunnel support, and the tunnel is in a stable state.

\subsubsection{Numerical Simulation for Extreme Rainfall Condition.} As shown in Figures 10-12, under the condition of extreme rainfall, with the two rows of antislide piles as the dividing point, there are three obvious deformation areas. The middle area showed the largest deformation of $159 \mathrm{~mm}$. The maximum deformation of the two rows of the antislide pile was $39.78 \mathrm{~mm}$; the deformation of the right-line tunnel was larger with the maximum value of $12.87 \mathrm{~mm}$, while the leftline tunnel did not deform.

As shown in Figure 13, under this extreme condition, the left-line tunnel was impacted by the tensile stress at the vault and bottom of the arch, and the maximum tensile stress was $0.44 \mathrm{MPa}$, equating to $18.33 \%$ of the ultimate tensile strength

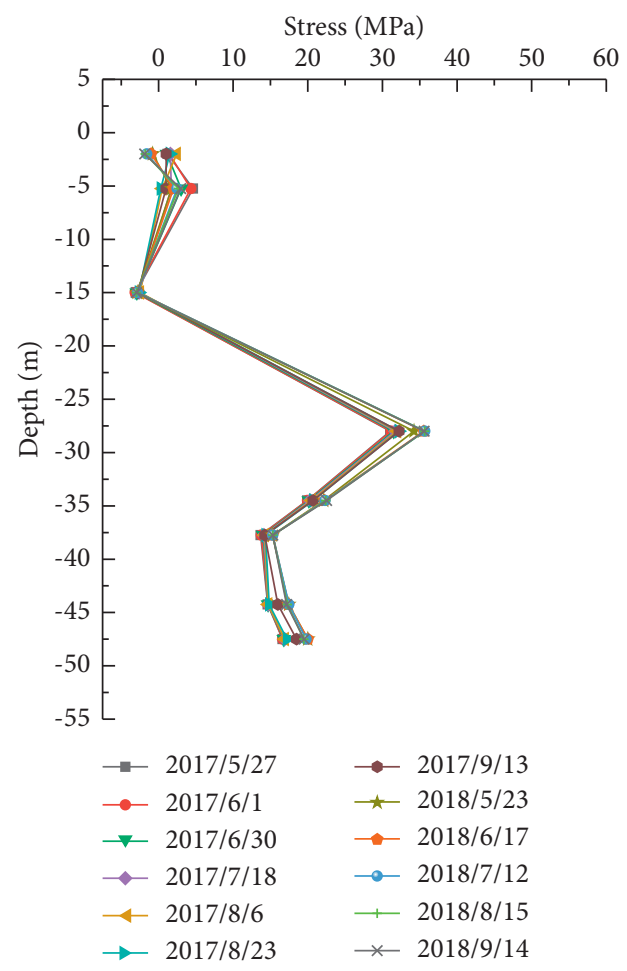

FIGURE 8: The body stress of $14 \#$ antislide pile during the rainy season.

of concrete, and the structure of the left-line tunnel was not obviously influenced. The right-line tunnel was affected by obvious tensile stress at the bottom and waist of the arch, and the maximum tensile stress is $2.24 \mathrm{MPa}$, equating to $93.3 \%$ of the ultimate tensile strength of concrete, which seriously affects the structural safety of the tunnel.

As shown in Figure 14, the left-line tunnel did not show plastic failure because it is located in the bedrock layer. However, the right-line tunnel is buried relatively shallow and located at the interface of soil and rock, so obvious plastic failure was found even under the retaining action of two rows of antislide piles in the slope; the failure type is mainly shear failure at the bottom and waist of the arch.

\subsection{Long-Term Monitoring and Analysis of the Influence of Landslides on Tunnel Engineering under Earthquake Condition}

3.2.1. Analysis of Actual Seismic Condition. As shown in Figure 15, under the disturbance of the earthquake, the antislide pile was resulting in a maximum displacement of 


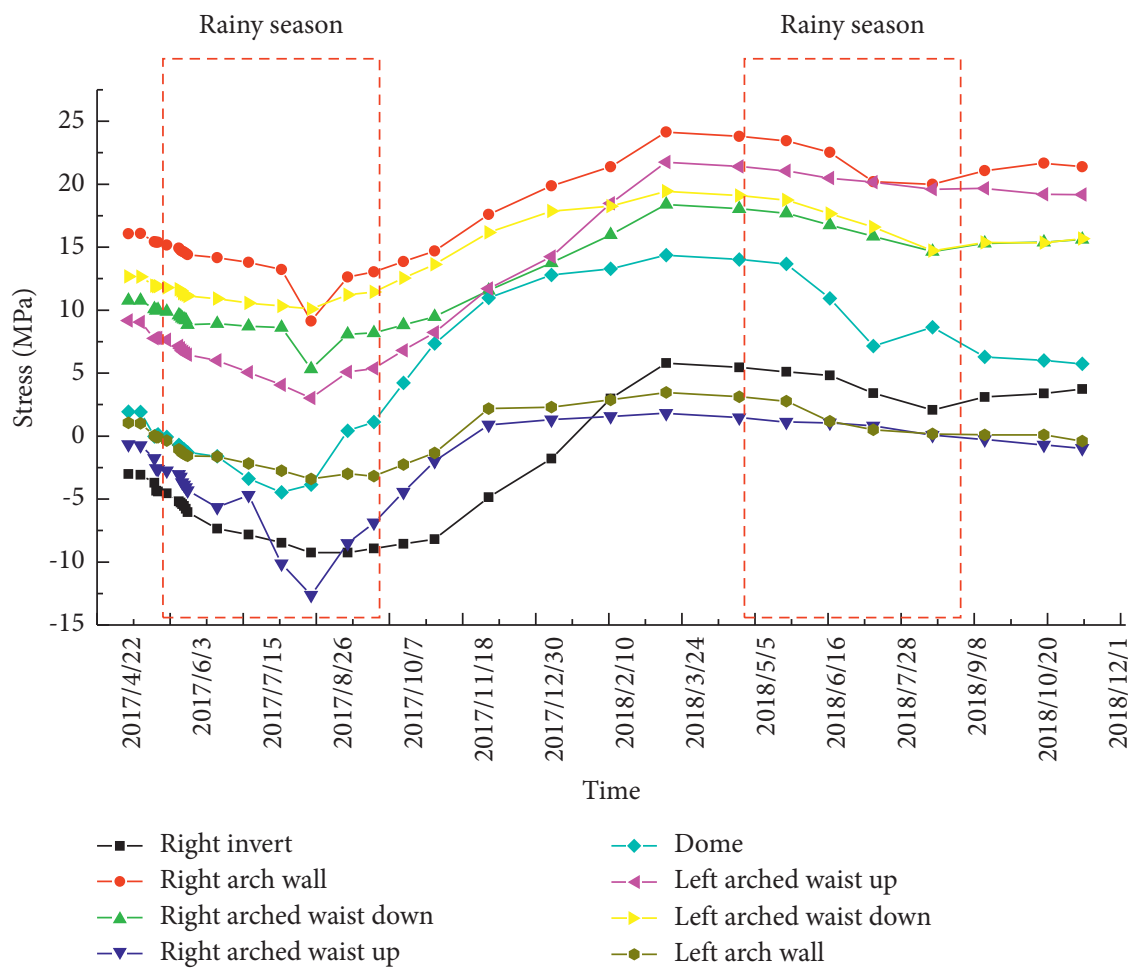

FIGURE 9: Variation curve of tunnel stress after initial support.

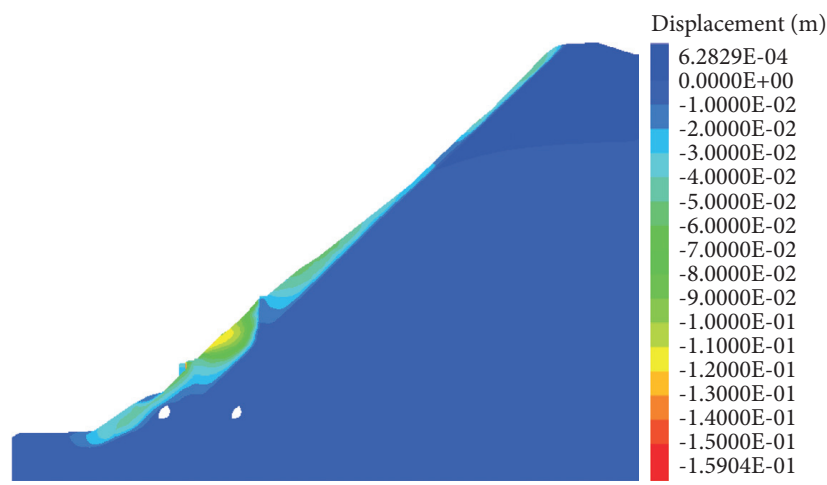

Figure 10: Cloud diagram of horizontal displacement of slope.

$3.7 \mathrm{~mm}$; the relatively small displacement indicates that the antislide pile played a good supporting role, and the whole landslide is in a stable state under the condition of a 6magnitude earthquake.

As shown in Figure 16, under this condition, the antislide pile stress generally shows a gradually increasing trend with a relatively small value, and there is no significant stress change, indicating that it has a good retaining effect and is in a stable state.

As shown in Figure 17, after the secondary lining, the tunnel stress was declining and gradually stabilized before the earthquake. However, due to the impact of the earthquake, its changing trend changed to a continuous and slow rise, and the stress eventually increased by more than $25 \%$ and finally stabilized; this shows that under the impact of the earthquake, the safety and stability of tunnel will be affected to a certain extent.
3.2.2. Numerical Simulation for Extreme Earthquake Condition. As shown in Figures 18-20, under the 8-magnitude seismic, the slope deformation characteristics are similar to those under extreme rainfall condition. There are 3 obvious deformation areas. The maximum deformation of the soil between the two rows of antislide piles is $229.75 \mathrm{~mm}$, and the largest deformation of antislide piles is $53.37 \mathrm{~mm}$; the deformation of the right-line tunnel is large with a maximum value of $14.53 \mathrm{~mm}$, while the left-line tunnel did not show deformation.

As shown in Figure 21, the mechanical characteristics of the tunnel are also similar to those under the condition of extreme rainfall. The left-line tunnel is affected by tensile stress at the vault with the maximum value of $0.70 \mathrm{MPa}$, equating to $29.2 \%$ of the ultimate tensile strength of the concrete, which does not cause significant damage to the 


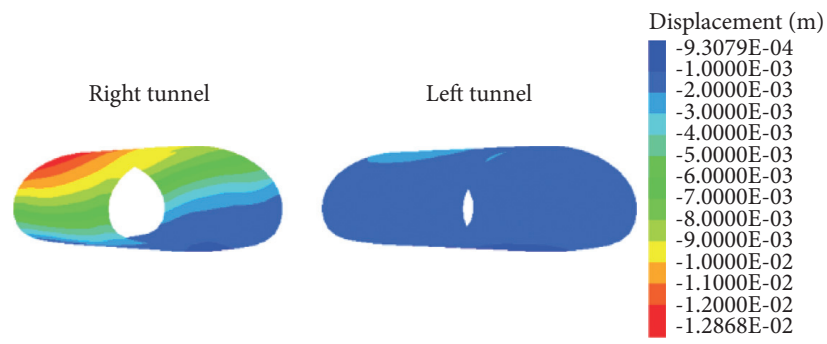

Figure 11: Cloud diagram of horizontal displacement of tunnel.

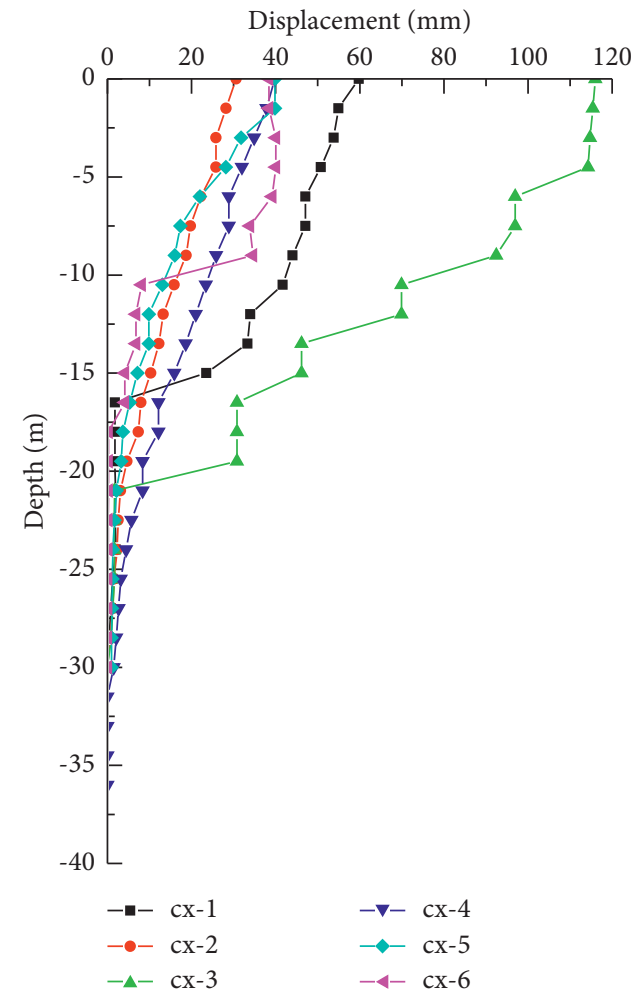

FIGURE 12: The curve of deep displacement of the landslide under extreme rainfall.

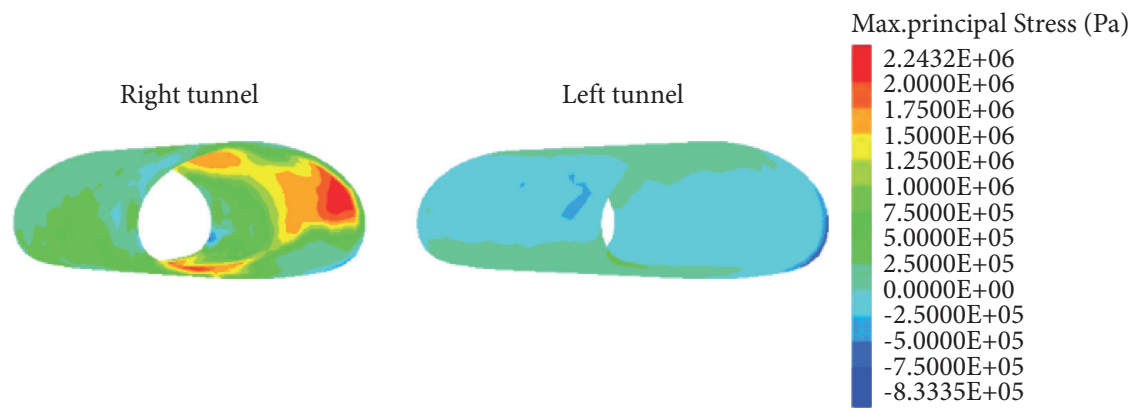

FIGURE 13: Cloud diagram of tunnel stress. 

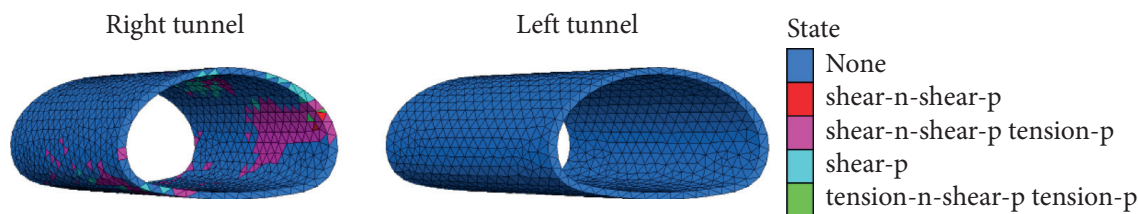

FIGURE 14: Cloud map of plastic zone distribution of the tunnel.

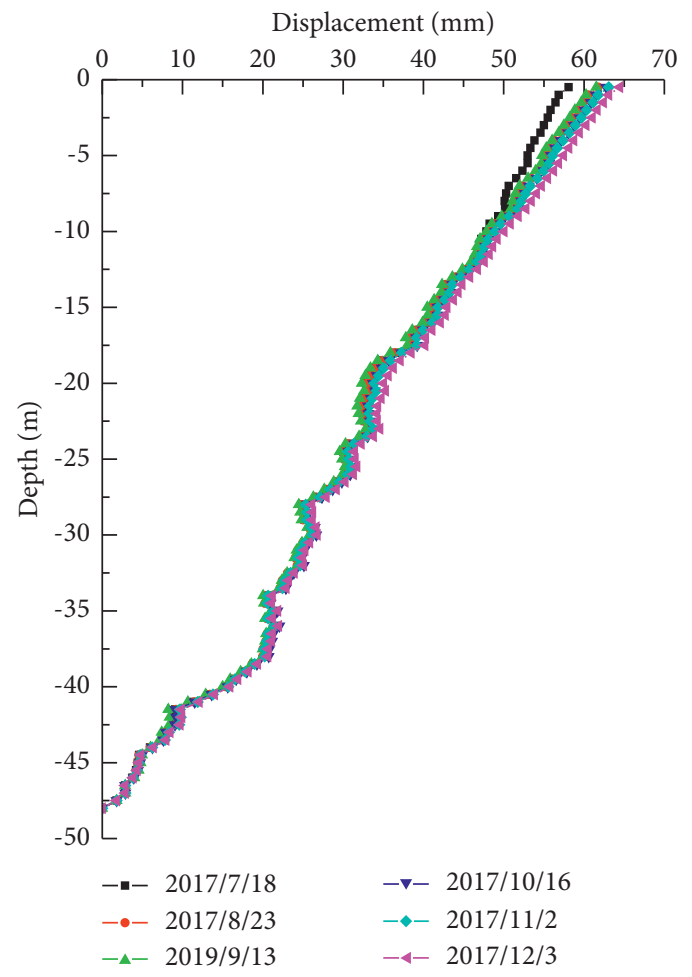

FIGURE 15: Curve of deep displacement of 14\# antislide pile during the earthquake.

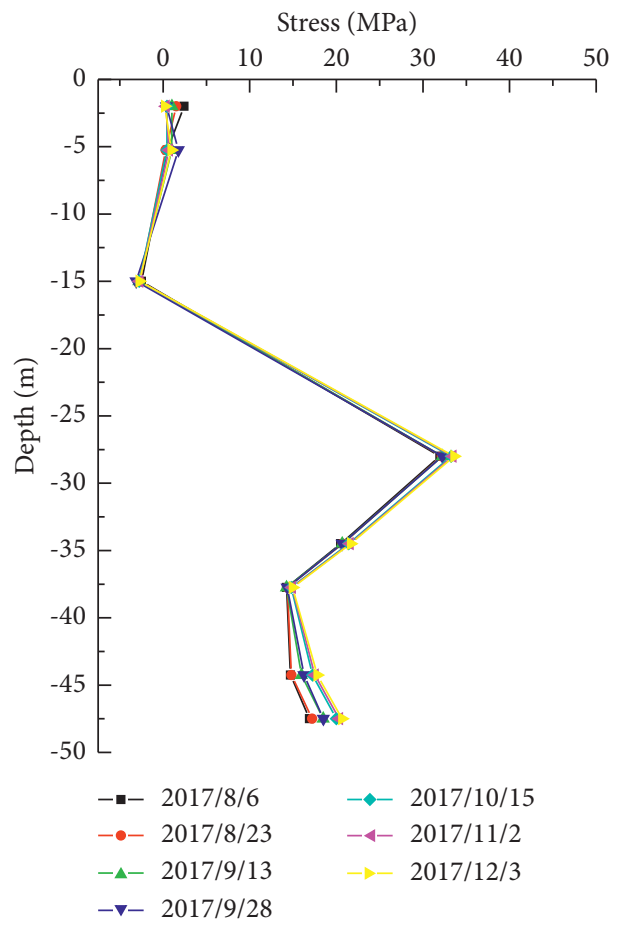

FIGURE 16: Pile body stress of 14\# antislide pile during the earthquake. 


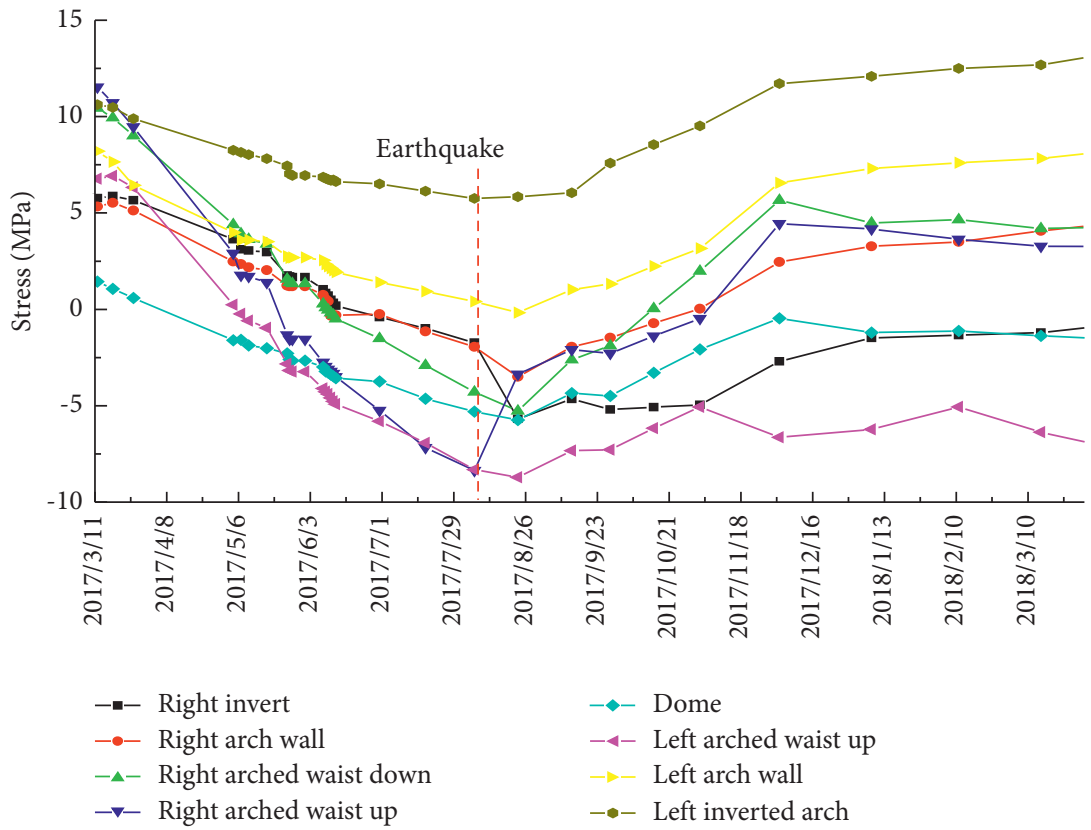

FIgURE 17: Stress curve after the secondary lining.

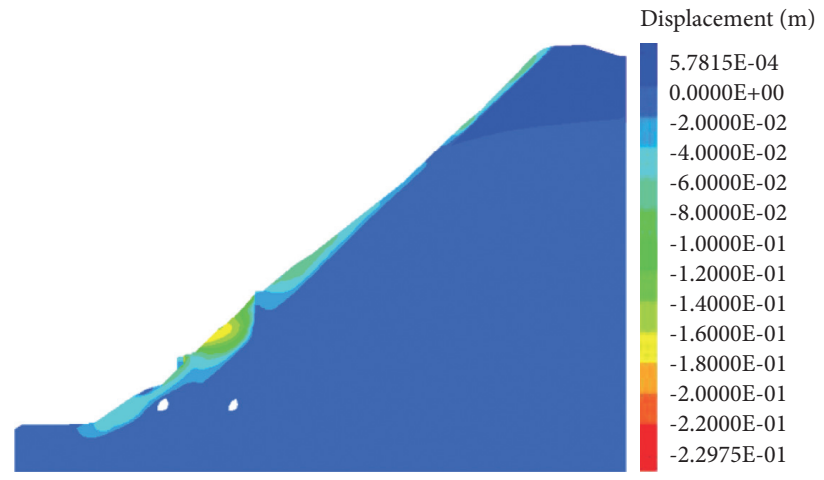

Figure 18: Cloud diagram of horizontal displacement of slope.

left-line tunnel structure. The right-line tunnel is affected by obvious tensile stress at the vault, arch bottom, and arch waist with the maximum value of $2.25 \mathrm{MPa}$, equating to $93.8 \%$ of the ultimate tensile strength of concrete, which seriously affects the structural safety of the tunnel.

As shown in Figure 22, the failure characteristics of the plastic zone are also similar to extreme rainfall conditions. The left-line tunnel did show plastic failure while the rightline tunnel showed obvious plastic failure, which is mainly manifested by shear failure at the arch top, arch bottom, and arch waist.

\section{Long-Term Monitoring Analysis of Influence of Tunnel Engineering on Landslide}

4.1. Analysis of Actual Construction. During the construction of the tunnel steps from September 1, 2016, to September 18, 2016, the stress of the antislide piles was always in a state of slow growth, and the maximum stress increased by 1.29 MPa, with an average daily increase of $71.7 \mathrm{KPa}$.

During the construction of the invert and initial support of the tunnel from September 18, 2016, to September 30, 2016, the stress growth of antislide piles was accelerated, and the maximum stress increased by $2.58 \mathrm{MPa}$, with an average daily increase of $198.5 \mathrm{KPa}$.

As shown in Figure 23, the shortest distance between the right-line tunnel and the $14 \#$ antislide pile is $2.12 \mathrm{~m}$. The antislide pile produced a maximum deformation of $30.00 \mathrm{~mm}$ from the beginning of tunnel excavation to the completion of initial support.

As shown in Figure 24, the tunnel construction induces an increase in the deformation of the antislide pile and the rate of stress changes. However, after the tunnel construction, the changing rate of deformation and stress decreased and remained stable. It shows that during the construction of the antislide pile, it has a certain impact on the deformation of the antislide pile without effect on the safety of the slope. 


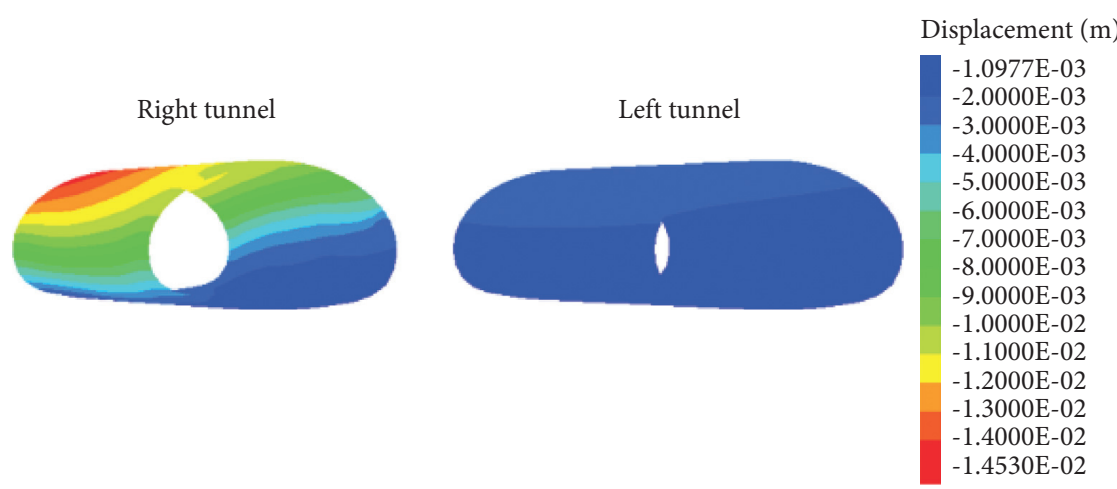

Figure 19: Cloud map of horizontal displacement of the tunnel.

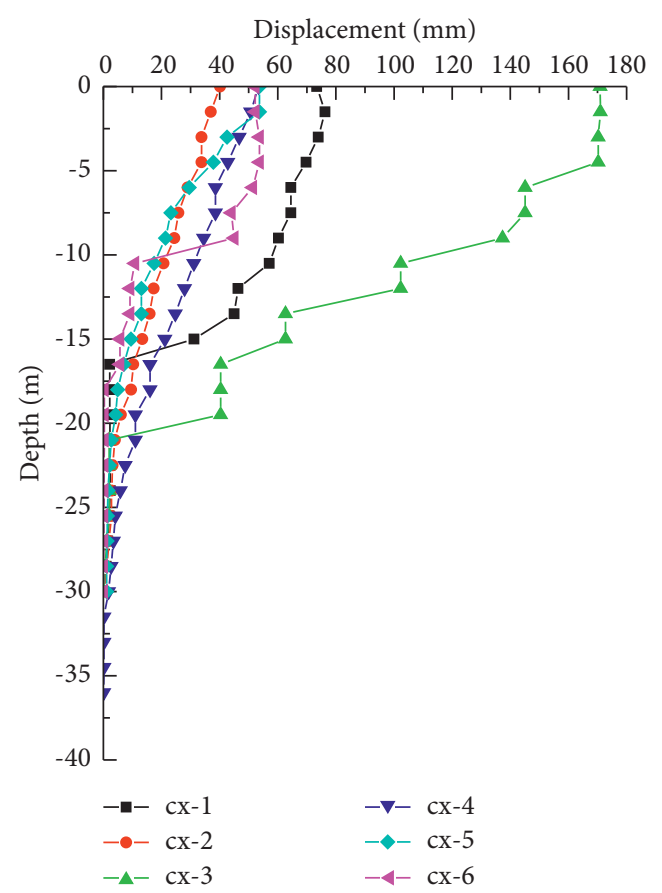

Figure 20: The deep displacement curve of the landslide body under extreme earthquake.

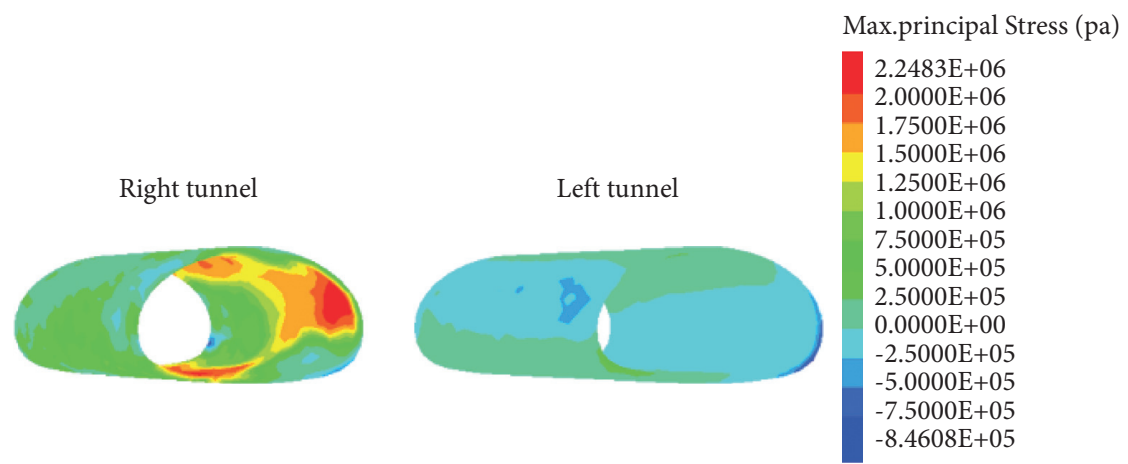

FIgURE 21: Cloud diagram of the maximum principal stress of the tunnel.

4.2. Numerical Simulation for Construction. As shown in Figures 25 to 26, during the construction, the maximum deformation of the landslide was $150.15 \mathrm{~mm}$, of which the 14\# antislide pile produced a displacement of $33.5 \mathrm{~mm}$; this indicates that the tunnel construction has a certain impact on the stability of the landslide and the deformation of the antislide piles. Reasonable design of position relationship between tunnel structure and antislide pile is able to avoid 


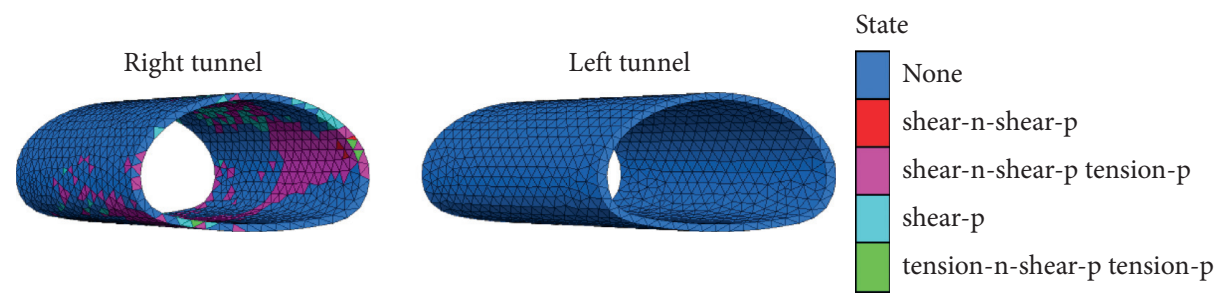

FIGURE 22: Distribution cloud map of tunnel shaping area.

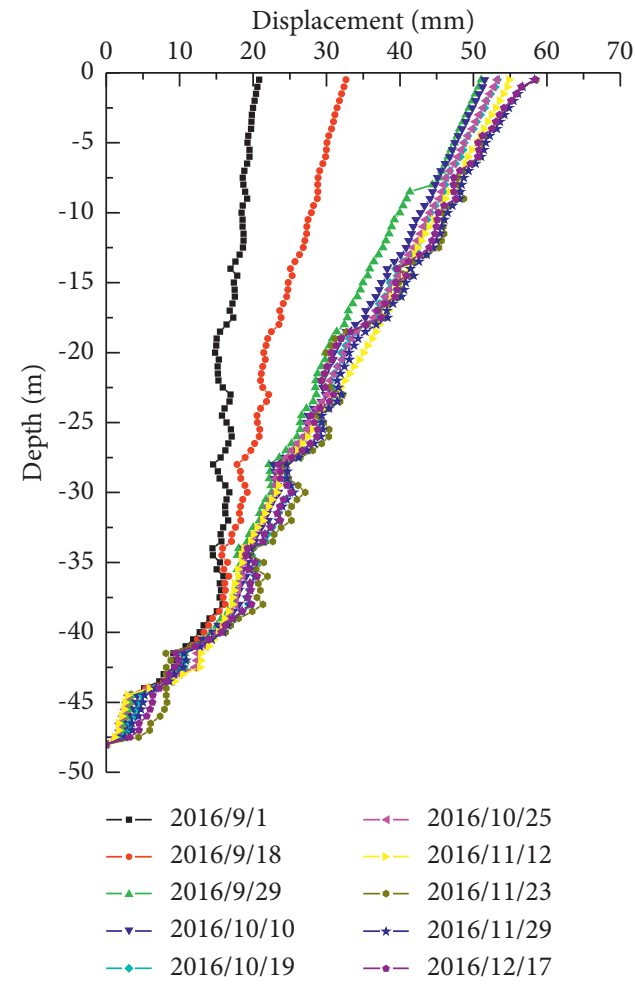

FIGURE 23: Deep displacement curve of 14\# antislide pile during construction. 


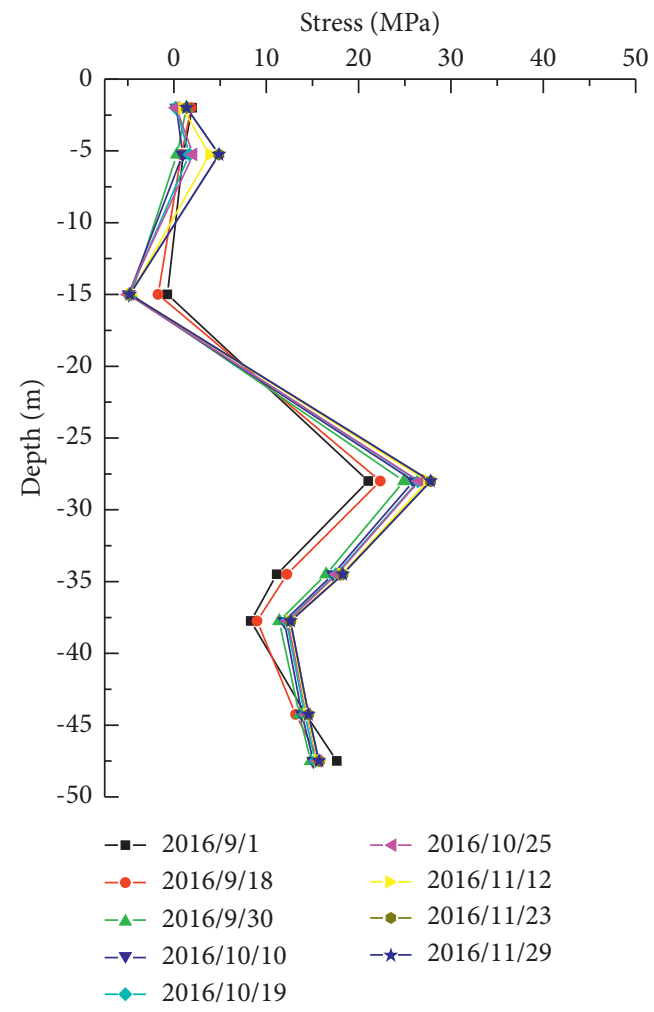

FIGURE 24: Stress curve of the deep part of 14\# antislide pile during construction.

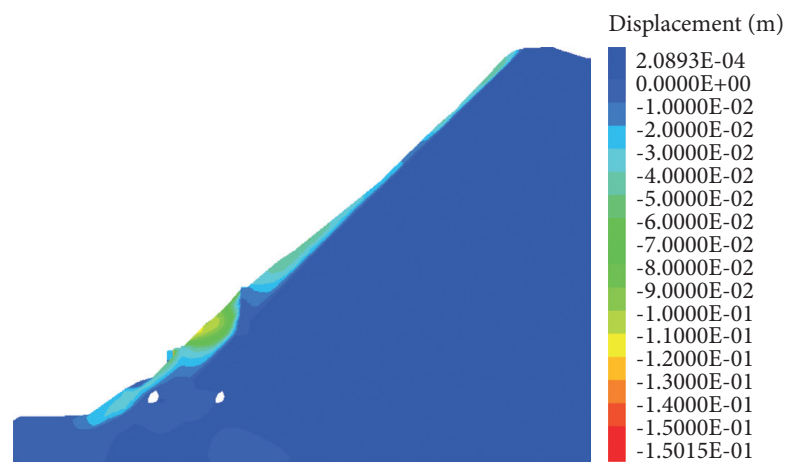

FIGURE 25: Cloud diagram of horizontal displacement of slope. 


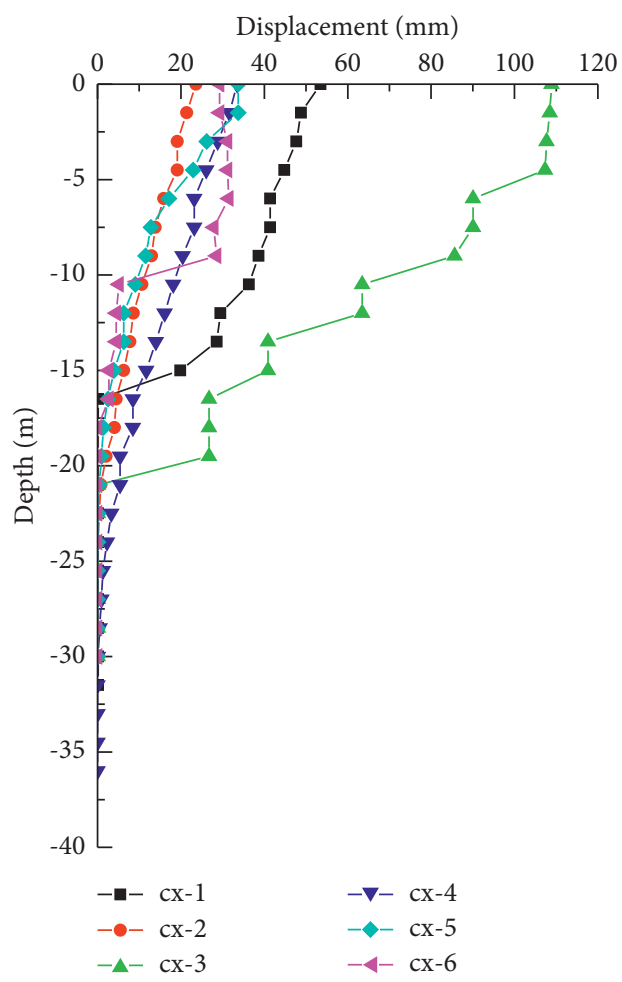

Figure 26: The deep displacement curve of the landslide under construction condition.

the influence of construction on retaining structure and slope as far as possible.

\section{Conclusion and Discussion}

Based on a railway tunnel project, the field monitoring test and numerical analysis were carried out on the landslide. The interaction mechanism between landslide and tunnel engineering is analyzed.

(1) Under conditions such as rainfall and earthquakes, the original internal stress balance of the landslide body is broken, which causes the landslide thrust to increase continuously. The landslide body presents a downward creeping trend, and the lower slope produces compression deformation and transmits the compressive force to the tunnel, resulting in the damage of linin.

(2) The excavation of the tunnel causes the surrounding rock to relax and deform, destroy the stress balance of the slope, and cause the slope to have a downward creep trend, which leads to the continuous increase in the landslide thrust, which eventually acts on the tunnel, resulting in deformation and damage of the tunnel.

(3) During the monitoring, under the influence of rainfall and earthquake, after the second lining, the tunnel stress continued to increase by $25 \%$. The antislide pile at a distance of $2.12 \mathrm{~m}$ showed a maximum deformation of $30 \mathrm{~mm}$ dung tunnel construction. The slope and the tunnel were affected but overall remained stable.

(4) Under extreme conditions such as rainfall and earthquakes, shear failures occurred at the vault, bottom, and waist of the right-line tunnel located at the junction of soil and rock, and the tensile strength of the right-line tunnel reached $93.3 \%$ and $93.8 \%$ of the limit value. Aiming at the weak part of the tunnel structure being damaged by shear and tension, the safety of the structure is reinforced by increasing the design thickness of the concrete, enhancing the strength of the concrete and increasing the density of planting bars.

\section{Data Availability}

The data used to support the findings of this study are available from the corresponding author upon request.

\section{Conflicts of Interest}

The authors declare that they have no conflicts of interest.

\section{Acknowledgments}

This research was funded by National Key R\&D Program of China (No. 2018YFC1504901), China Railway Corporation Research and Development of Science and Technology Plan Project (No. P2018G001), and National Railway Group Science and Technology Research and Development Program (No. N2020G052). 


\section{References}

[1] H. Wu, Research on Deformation Mechanism and Control Technology of Tunnel-Landslide System, China Academy of Railway Sciences, Beijing, China, 2012.

[2] K. Konagai, M. Numada, A. Zafeirakos, J. Johansson, A. Sadr, and T. Katagiri, "An example of landslide-inflicted damage to tunnel in the 2004 Mid-Niigata Prefecture earthquake," Landslides, vol. 2, no. 2, pp. 159-163, 2005.

[3] Y. Zheng, Study on the Slope Stability of the Tunnel Entrance, Chongqing University, Chongqing Shi, China, 2008.

[4] Y. Zhang, J. Tang, Z. He, and H. Zhao, "Safety distance and stability analysis of tunnel crossing landslide body orthogonally," Rock and Soil Mechanics, vol. 38, no. 11, pp. 3278-3286, 2017.

[5] R. Huang and H. Xiao, "Deformation mechanism of a shallow double-arch tunnel in a sloping rock mass," Bulletin of Engineering Geology and the Environment, vol. 69, no. 1, pp. 89-97, 2010.

[6] D. Song, J. Chen, and J. Cai, "Deformation monitoring of rock slope with weak bedding structural plane subject to tunnel excavation," Arabian Journal of Geosciences, vol. 11, no. 11, p. 251, 2018.

[7] H. Wu, D. Wu, H. Ma, and L. Zhang, "Research on the types of tunnel-landslide system and tunnel deformation mode," Chinese Journal of Rock Mechanics and Engineering, vol. 31, no. S2, pp. 3632-3642, 2018.

[8] J. Yi, R. Deng, Z. Zhong, K. Li, and C. Sun, "Analysis of the law of force and deformation and influencing factors of tunnels crossing the landslide deformation zone," Chinese Journal of Rock Mechanics and Engineering, vol. 35, no. S2, pp. 36153625, 2016.

[9] K. Zhu, Analysis of Slope-Tunnel Interaction and Application of Mathematical Quadratic Programming, Tongji University, Shanghai, China, 2007.

[10] Z. Tao, Research on Tunnel Deformation Mechanism and Disaster Prediction and Treatment in Landslide Section, Southwest Jiaotong University, Chengdu, China, 2003.

[11] M.-f. Lei, D.-y. Lin, W.-c. Yang, C.-h. Shi, L.-m. Peng, and J. Huang, "Model test to investigate failure mechanism and loading characteristics of shallow-bias tunnels with small clear distance," Journal of Central South University, vol. 23, no. 12, pp. 3312-3321, 2016.

[12] Y. Zhang, Research on Deformation Mechanism and Prevention and Control Technology of Shallow-Buried Expansive Soil Tunnel in Landslide Section, Xi'an: Chang'an University, China, Shaanxi, 2019.

[13] M. Yang, Q. Sun, W.-c. Li, and K. Ma, “Three-dimensional finite element analysis on effects of tunnel construction on nearby pile foundation," Journal of Central South University, vol. 18, no. 3, pp. 909-916, 2011.

[14] Y. Zhang, J. Yang, and F. Yang, "Field investigation and numerical analysis of landslide induced by tunneling," Engineering Failure Analysis, vol. 47, no. A, pp. 25-33, 2015.

[15] Z. Tao, Y. Shu, X. Yang, Y. Peng, Q. Chen, and H. Zhang, "Physical model test study on shear strength characteristics of slope sliding surface in Nanfen open-pit mine," International Journal of Mining Science and Technology, vol. 30, no. 3, pp. 421-429, 2020.

[16] R. Vassallo, M. Mishra, G. Santarsiero, and A. Masi, "Modeling of landslide-tunnel interaction: the varco d'Izzo case study," Geotechnical \& Geological Engineering, vol. 37, no. 6, pp. 5507-5531, 2019.
[17] J.-h. Liu, X.-m. Liu, Y.-j. Zhang, and T. Xiao, "Numerical analysis and field monitoring tests on shallow tunnels under weak surrounding rock," Journal of Central South University, vol. 22, no. 10, pp. 4056-4063, 2015.

[18] S.-y. Fan, Z.-p. Song, Y.-w. Zhang, and N.-f. Liu, "Case study of the effect of rainfall infiltration on a tunnel underlying the roadbed slope with weak inter-layer," KSCE Journal of Civil Engineering, vol. 24, no. 5, pp. 1607-1619, 2020.

[19] L. Causse, R. Cojean, and J.-A. Fleurisson, "Interaction between tunnel and unstable slope - influence of time-dependent behavior of a tunnel excavation in a deep-seated gravitational slope deformation," Tunnelling and Underground Space Technology, vol. 50, pp. 270-281, 2015.

[20] M. P. Komu, U. Guney, T. E. Kilickaya, and C. Gokceoglu, "Using 3D numerical analysis for the assessment of tunnellandslide relationship: bn tunnel (south of Turkey)," Geotechnical \& Geological Engineering, vol. 38, no. 2, pp. 12371254, 2020.

[21] Z. Zhang, Q. Zhao, C. Xu, and Y. Yang, "Interaction analyses between tunnel and landslide in mountain area," Journal of Mountain Science, vol. 14, no. 7, pp. 1124-1139, 2017. 